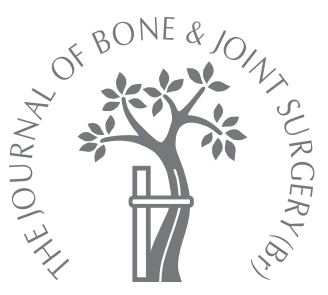

C. J. Pendegrass,

D. Gordon, C. A. Middleton, S. Ng. Man Sun, G. W. Blunn

From the Royal

National

Orthopaedic

Hospital, Stanmore, England

\title{
Sealing the skin barrier around transcutaneous implants
}

\author{
IN VITRO STUDY OF KERATINOCYTE PROLIFERATION AND \\ ADHESION IN RESPONSE TO SURFACE MODIFICATIONS OF \\ TITANIUM ALLOY
}

\begin{abstract}
Conventional amputation prostheses rely on the attachment of the socket to the stump, which may lead to soft-tissue complications. Intraosseous transcutaneous amputation prostheses (ITAPs) allow direct loading of the skeleton, but their success is limited by infection resulting from breaching of the skin at the interface with the implant.

Keratinocytes provide the skin's primary barrier function, while hemidesmosomes mediate their attachment to natural ITAP analogues. Keratinocytes must attach directly to the surface of the implant. We have assessed the proliferation, morphology and attachment of keratinocytes to four titanium-alloy surfaces in order to determine the optimal topography in vitro. We used immunolocalisation of adhesion complex components, scanning electron microscopy and transmission electron microscopy to assess cell parameters.

We have shown that the proliferation, morphology and attachment of keratinocytes are affected by the surface topography of the biomaterials used to support their growth. Smoother surfaces improved adhesion. We postulate that a smooth topography at the point of epithelium-ITAP contact could increase attachment in vivo, producing an effective barrier of infection.
\end{abstract}

Metal implants which temporarily or permanently breach the natural barrier of the skin to infection have a number of clinical applications. Examples include dental and auricular implants anchored to bone, external fixators and Ilizarov frames, and intraosseous transcutaneous amputation prostheses. Extraoral examples of transcutaneous implants may fail in a number of ways including marsupialisation with epithelial downgrowth and pocket formation leading to the implant becoming extracutaneous, mechanical avulsion, and infection, ${ }^{1}$ which is the most common complication and occurs in $53 \%^{2}$ to $100 \%{ }^{3,4}$ of cases.

In amputees conventional stump-socket designs transfer forces from the patient to a point of external contact through the remainder of the prosthesis. Non-uniform distribution of pressure at the stump-socket interface can lead to pain, infection and necrosis of the soft tissues. ${ }^{5,6}$ Conventional prostheses also generate an unnatural microbial environment at this site. ${ }^{7}$ Intraosseous transcutaneous amputation prostheses (ITAPs) could overcome these problems by allowing the external implant to be attached directly to the skeleton through a transcutaneous abutment. This would transfer forces directly from the prosthesis to the skeleton, eliminating the role of the soft tissues. Transcutaneous implants have been used clinically since the 1960s, when Branemark et al ${ }^{8-10}$ pioneered the use of dental and auricular implants which penetrated the skin and were anchored to bone. Despite subsequent attempts to utilise similar implants in amputees, their success has been limited by loosening of the implant, mechanical failure and infection. ${ }^{11}$ We have previously demonstrated that in natural analogues of ITAPs there is a tight seal between the soft-tissue layers and the structure penetrating the skin. ${ }^{12}$ Using this analogue, we have developed a flanged ITAP which optimises dermal attachment and reduces epithelial downgrowth by minimising the stresses at the soft-tissue implant interface. ${ }^{13}$ However, consistent epithelial attachment has not been observed. We consider this to be a prerequisite if an ITAP is to be used clinically. Early epithelial attachment within the first 24 to 48 hours after implantation is crucial if epithelial downgrowth is to be prevented. Changes in the surface topography of the substrate have been shown to affect the cell-biomaterial interface, ${ }^{14-16}$ with cell density, morphology and attachment being influenced in vitro. With an ITAP, the adhesion of epithelial cells to the implant is fundamental for preventing infec- 
tion, although in vivo the migration of epithelial cells through the dermis will necessitate dynamic cellular adhesion at the skin-implant interface. In our department, machine-finished, smooth-polished, sand-blasted and acidetched titanium alloy surfaces are routinely used in the manufacture, research and clinical trialing of orthopaedic implants. We undertook this study in order to determine the effect of these different surface topographies on the proliferation, morphology and attachment of keratinocytes in vitro. By determining which of these optimised the attachment of keratinocytes, we aimed to translate our findings into the development of the surface topography of ITAPs.

Focal adhesions are one of the mechanisms by which cells adhere to an underlying substratum, and immunolabelling of vinculin, one of the molecular components of focal adhesions, has been used as a quantifiable assessment for measuring cell attachment. ${ }^{17}$ In vivo, keratinocytes use hemidesmosomes for the attachment to basement membranes. ${ }^{18}$ The integrin $\alpha 6 \beta 4$ is the principal agent mediating this transmembrane integration, ${ }^{19}$ while plectin has a role in clustering $\alpha 6 \beta 4$ integrins at the basal cell edge. ${ }^{20}$ Bullous pemphigoid antigen II (BP 180) is another transmembrane component of the hemidesmosome, to which it is specifically localised. ${ }^{18}$ Immunolocalisation of $\alpha 6 \beta 4$, plectin and BP 180 can be used to measure the attachment of keratinocytes.

\section{Materials and Methods}

Substrate biomaterials. Titanium alloy $\left(\mathrm{Ti}_{6} \mathrm{~A}_{1} \mathrm{~V}\right)$ discs, $10 \mathrm{~mm}$ in diameter, were manufactured from surgical grade titanium alloy (BS7252 PT3). Four routine surface topographies were applied: machine-finished, smoothpolished, sand-blasted and hydrofluoric acid-etched. Machine-finished discs were cut from surgical grade titanium alloy rods and used without further processing. Smooth-polished discs were prepared by successive mechanical polishing with P1200 to P4000 grade polishing paper and Buehler Micropolish $1.0 \mathrm{~mm}$ alumina (Buehler, Coventry, United Kingdom) on an Exact-MicroGrinding system (Mederex, Bath, United Kingdom). Sandblasting was applied by firing discs with $0.1 \mathrm{~mm}$ and $0.5 \mathrm{~mm}$ aluminium oxide grit (1:1) (Guyson International Ltd, Hitchin, United Kingdom) in a sealed cabinet, and acid-etching was achieved by placing the discs in $2 \%$ hydrofluoric acid for 15 minutes. The discs were cleaned and sterilised to the level required for the manufacture of orthopaedic implants.

Substrate characterisation. Surface roughness $(\mathrm{Ra})$, the mean maximum height of the profile $(\mathrm{Rz})$ and the mean spacing of irregularities of the profile $(\mathrm{Sm})$ were measured using a Mitutoyo Surftest SV-400 Surface Profiler (Mitutoyo, Warwick, United Kingdom), and profile imaging was performed using a JEOL JSM-550LV scanning electron microscope (JEOL Ltd., Tokyo, Japan), on six specimens of each type of substrate.
Biomaterial allocation. A total of 51 discs of each of the four substrate biomaterials was prepared. Of these, 24 discs of each type were allocated for proliferation and immunofluorescent microscopy, six for each time point of 24, 48, 72 and 96 hours. A further 24 of each were allocated for scanning electron microscopy (SEM) analysis, six for each time point of 24, 48, 72 and 96 hours, and three of each for transmission electron microscopy at 72 hours.

Cell culture. Immortalised human keratinocytes, shown to retain the differentiated characteristics and phenotype of normal keratinocytes in vitro, were cultured in Roswell Park Memorial Institute 1640 medium (Invitrogen, Paisley, United Kingdom) supplemented with $10 \%$ fetal calf serum, L-glutamine (First Link, Birmingham, United Kingdom), penicillin and streptomycin (Invitrogen) at $37^{\circ} \mathrm{C}$ in $5 \%$ $\mathrm{CO}_{2}$. Of these, $2 \times 10^{4}$ cells were seeded per disc and analyses were undertaken at 24, 48, 72 and 96 hours.

Proliferation. This was assessed before performing immunofluorescent microscopy. Alamar Blue (Serotec, Oxford, United Kingdom) was diluted 1 in 10 with phenol red-free Dulbecco's modified Eagle's medium (Invitrogen) and applied to the wells of the cell substrate for four hours. Two $100 \mathrm{ml}$ aliquots were removed from each well, transferred to a 96-well plate, and absorbance was measured at $570 \mathrm{~nm}$ (reference wavelength $630 \mathrm{~nm}$ ) by a Fluoroskan Ascent plate reader (Labsystems, Farnborough, United Kingdom).

Immunofluorescent microscopy. The cells were fixed in $10 \%$ formal saline, permeabilised with $0.05 \%$ Triton X-100 (T8787, Sigma Aldrich, Dorset, United Kingdom) and incubated with primary antibodies according to the following protocols.

Hemidesmosomal components such as the $\alpha 6$-integrin sub-unit and BP 180 were immunolocalised with antibody preparations of mouse monoclonal anti- $\alpha 6$-integrin (I6653, Sigma-Aldrich) and rabbit monoclonal anti-BP 180 (University of Nagoya, Nagoya, Japan) at $10 \mathrm{mg} / \mathrm{ml}$ and 1:200 $\mathrm{ml}$ in sterile phosphate-buffered saline (PBS) respectively, for two hours.

The vinculin components of focal adhesions were immunolocalised using mouse monoclonal anti-vinculin (V9131, Sigma-Aldrich) 1:112 $\mathrm{ml}$ in sterile PBS for two hours.

After three successive washes in PBS for five minutes, primary antibodies were located using fluoresceinisothiocyanate labelled anti-mouse antibodies (F2883 Sigma-Aldrich), 1:68 ml in sterile PBS for one hour, or Alexa Fluor 568 labelled anti-rabbit antibodies (A11036, Invitrogen). The samples were washed thoroughly before examination using an Olympus BH-2-RFCA photomicroscope (Olympus Optimal Company Ltd, Tokyo, Japan), and analysed using a Zeiss microscope with Axioimage (version 4.4) image-analysis software (Carl Zeiss Ltd, Welwyn Garden City, United Kingdom) with 15 random fields of view assessed per disc. The number of focal adhesions/hemidesmosomes per unit cell area was calculated by dividing the 
Table I. The median values ( $\mu \mathrm{m} ; 95 \%$ confidence intervals) for surface roughness (Ra), maximum height of the profile $(\mathrm{Rz})$ and the spacing of irregularities of the profile $(\mathrm{Sm})$ for all types of surface

\begin{tabular}{llll}
\hline Surface type & $\mathbf{R a}$ & $\mathbf{R z}$ & $\mathbf{S m}$ \\
\hline Smooth-polished & $0.030(0.12$ to 0.048$)$ & $0.120(0.099$ to 0.146$)$ & 20.760 (9.877 to 32.719$)$ \\
Machine-finished & $0.305(0.212$ to 0.363$)$ & $1.405(0.936$ to 1.784$)$ & 37.960 (33.063 to 45.002) \\
Sand-blasted & $0.935(0.821$ to 1.034$)$ & $4.445(3.256$ to 6.474$)$ & 63.640 (41.455 to 98.136) \\
Acid-etched & $0.205(0.175$ to 0.230$)$ & $1.110(0.975$ to 1.270$)$ & 31.430 (27.797 to 34.343) \\
\hline
\end{tabular}

number of visible markers in each cell by its area, using Zeiss Axioimage software for all cells within each field of view, on six discs of each type of material. BP 180 positive staining was used to confirm that the patterning of $\alpha 6$ integrin staining was localised to hemidesmosomes. For the purpose of this study, only needle-shaped structures greater than $3 \mathrm{~mm}$ long, consistent with what are conventionally accepted as focal adhesion plaques, were considered to be positive counts for focal adhesions. Colocalisation of BP 180 and the $\alpha 6$-integrin subunit was considered to be a prerequisite for a positive hemidesmosome count.

The immunolocalisation protocols were repeated omitting the primary antibody stages, and used as negative control groups.

Scanning electron microscopy. Cell morphology was assessed using a JEOL JSM-550LV scanning electron microscope $(10 \mathrm{kV})$, on six samples each at 24,48 and 72 hours. They were fixed in $1.5 \%$ glutaraldehyde in $0.1 \mathrm{M}$ sodium cacodylate buffer $(\mathrm{pH} \quad 7.2)$ treated with $1 \%$ osmium tetroxide and $1 \%$ tannic acid and dehydrated in an ascending alcohol series before air-drying in hexamethyldisalazane. The samples were gold-palladium sputtercoated in an Emitech K550 Sputter Coater (Emitech Ltd, Ashford, United Kingdom).

Transmission electron microscopy. Hemidesmosomes and focal adhesions were visualised using transmission electron microscopy after 72 hours. The cells were fixed in $1.5 \%$ glutaraldehyde, treated with $1 \%$ osmium tetroxide, dehydrated in an ascending alcohol series and embedded in araldite resin. In order to remove the discs from the embedded specimens, liquid nitrogen was applied to induce contraction of the metal and to allow separation from the cell monolayer. After removal of the disc the specimens were reembedded in araldite resin, sectioned to $90 \mathrm{~nm}$ using an LKB Ultratome (LKB, Stockholm, Sweden), stained with uranyl acetate and lead citrate, and examined using a Philips CM12 analytical transmission electron microscope (FEI, Cambridge, United Kingdom). Analyses were performed on three discs of each type of material.

Statistical analysis. Numerical data were analysed by SPSS version 12.0 for Windows (SPSS Inc., Chicago, Illinois). The data did not meet the assumptions required for parametric testing (Kolmogorov-Smirnov $\mathrm{p}>0.05$ ) and were therefore analysed using non-parametric tests. The Kruskal-Wallis test was used to determine the differences in
Table II. The median absorbance ( $\mu \mathrm{m} ; 95 \%$ confidence intervals) at various time points for all types of surface

\begin{tabular}{|c|c|c|}
\hline Surface & Time (hrs) & Absorbance \\
\hline \multirow[t]{4}{*}{ Smooth-polished } & 24 & 34.35 (31.51 to 36.20$)$ \\
\hline & 48 & $52.30(49.90$ to 54.10$)$ \\
\hline & 72 & 102.20 (99.98 to 115.26$)$ \\
\hline & 96 & 145.00 ( 128.42 to 149.36$)$ \\
\hline \multirow[t]{4}{*}{ Machine-finished } & 24 & 31.65 (29.91 to 33.48 ) \\
\hline & 48 & 47.65 (44.66 to 50.81 ) \\
\hline & 72 & 101.35 (80.55 to 146.25 ) \\
\hline & 96 & 126.30 (109.96 to 139.99$)$ \\
\hline \multirow[t]{4}{*}{ Sand-blasted } & 24 & 32.75 (31.06 to 35.76$)$ \\
\hline & 48 & 46.85 (44.60 to 47.62 ) \\
\hline & 72 & 87.55 (72.29 to 111.59$)$ \\
\hline & 96 & 104.15 (87.22 to 113.26$)$ \\
\hline \multirow[t]{4}{*}{ Acid-etched } & 24 & 34.10 (33.44 to 35.07$)$ \\
\hline & 48 & 47.75 (45.86 to 48.61$)$ \\
\hline & 72 & $86.95(81.45$ to 114.00$)$ \\
\hline & 96 & 141.20 (121.97 to 172.44$)$ \\
\hline
\end{tabular}

multiple sets of data, and the Mann-Whitney $U$ test to examine those between individual sets of data on a pairwise basis. Spearman's rank correlation was used to determine the significance of linear relationships between the test variables. All the data were collected using two-person blind assessments and checked for interobserver agreement by the Mann-Whitney U test. The results were considered to be significant at $\mathrm{p} \leq 0.05$.

\section{Results}

Substrate characterisation. The median values of $\mathrm{Ra}, \mathrm{Rz}$ and $\mathrm{Sm}$ with $95 \%$ confidence intervals (CI) are presented in Table I. Smooth-polished discs had significantly lower values compared with the machine-finished, sand-blasted or acid-etched discs (all p-values, < 0.05). The values for the sand-blasted discs were significantly higher than those of acid-etched or machine-finished discs and the latter had a significantly higher $\mathrm{Ra}$ than acid-etching, while no significant differences were observed for $\mathrm{Rz}$ or Sm.

Proliferation. The median absorbance values indicative of proliferative capacity are shown with $95 \%$ CI in Table II. Significant increases were observed between all time points for smooth-polished and acid-etched discs, and up 


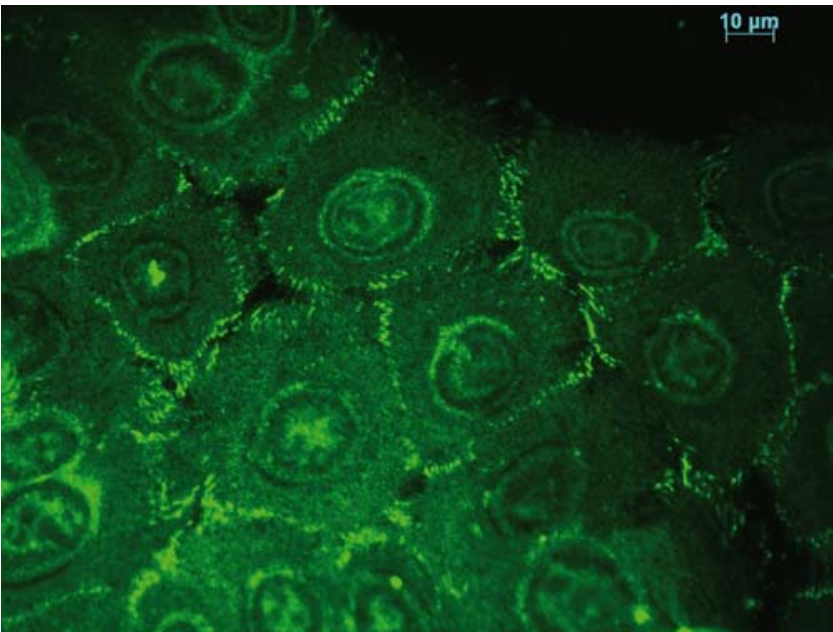

Fig. 1

Vinculin staining of focal contacts after 48 hours on smooth-polished discs.

to 72 hours for machine-finished and sand-blasted discs (all p-values, < 0.05). No significant increase was observed between 72 and 96 hours for the machine-finished or sandblasted substrates $(\mathrm{p}>0.05)$. At 24 hours, no significant differences were observed between any substrates (all pvalues, $<0.05)$. At 48 hours, smooth-polished discs supported immortalised human keratinocytes with significantly greater proliferation compared with sand-blasted, machine-finished and acid-etched discs (all pvalues, $<0.05)$. By 72 hours no significant differences were observed between smooth-polished and machine-finished or between sand-blasted and acid-etched discs (all p-values $>0.05$ ), with smooth-polished discs showing increased proliferation compared with both sand-blasted and acidetched discs $(\mathrm{p}<0.05)$. By 96 hours, proliferation on sandblasted discs was significantly lower than that in all of the remaining substrates (all p-values, $<0.05$ ).
Immunofluorescent microscopy. Cells stained positive for the $\alpha 6$-integrin subunit, BP 180 and vinculin. The vinculin staining appeared as distinct needle-shaped markers on the periphery of the cell (Fig. 1). The median numbers of focal adhesions per unit cell area (focal adhesions $/ \mu \mathrm{m}^{2}$ ) with $95 \%$ CIs are shown in Table III. The number increased between 24 and 48 hours, and between 48 and 72 hours on all types of disc (all p-values, < 0.05 ). At 24 and 48 hours, sand-blasted discs supported immortalised human keratinocytes with significantly lower numbers of focal adhesions per unit cell area compared with smooth-polished, machine-finished and acid-etched discs (all pvalues, $<0.05)$. No significant differences were observed for smooth-polished, machine-finished, and acid-etched discs at 24 hours, or between machine-finished and acidetched discs at 48 hours (all p-values, $<0.05$ ). At 48 and 72 hours, smooth-polished discs supported cells with significantly greater numbers of focal adhesions per unit cell area (all p-values, $<0.05$ ), while by 72 hours no significant differences were observed between the remaining substrates (all p-values, $<0.05$ ).

The $\alpha 6$-integrin subunit staining appeared within cells cultured on all of the titanium surfaces, with hemidesmosome association being confirmed by an identical localisation pattern for BP 180 (Fig. 2). The median number of hemidesmosomes per unit cell area (hemidesmosomes $/ \mu \mathrm{m}^{2}$ ) with $95 \%$ CIs is also shown in Table III. The number increased between 24, 48 and 72 hours on smooth-polished discs and between 24 and 48 hours on machine-finished discs (all p-values, $<0.05$ ). No significant differences were observed between 24 and 72 hours on either sand-blasted or acid-etched discs $(p>0.05)$. At 24 and 48 hours the number of hemidesmosomes per unit cell area was significantly lower on sand-blasted discs compared with smoothpolished, machine-finished and acid-etched discs (Table III) (all p-values, < 0.05). No significant differences were observed between machine-finished, sand-blasted and acidetched discs at 24 hours or between acid-etched and machine-finished discs at 48 hours (all p-values, > 0.05). At 48 hours smooth-polished substrates supported cells with

Table III. The median number of focal adhesions (focal adhesions $/ \mu \mathrm{m}^{2} ; 95 \%$ confidence intervals) and hemisdesmosomes per unit cell area (hemidesmosomes $/ \mu \mathrm{m}^{2} ; 95 \%$ confidence intervals) for all types of surface at 24,48 and 72 hours

\begin{tabular}{|c|c|c|c|}
\hline Surface type & 24 hours & 48 hours & 72 hours \\
\hline \multicolumn{4}{|l|}{ Focal adhesions } \\
\hline Smooth-polished & $2.25 \times 10^{-2}\left(2.13 \times 10^{-2}\right.$ to $\left.2.34 \times 10^{-2}\right)$ & $3.97 \times 10^{-2}\left(3.70 \times 10^{-2}\right.$ to $\left.4.57 \times 10^{-2}\right)$ & $7.98 \times 10^{-2}\left(7.30 \times 10^{-2}\right.$ to $\left.8.50 \times 10^{-2}\right)$ \\
\hline Machine-finished & $2.17 \times 10^{-2}\left(2.08 \times 10^{-2}\right.$ to $\left.2.63 \times 10^{-2}\right)$ & $3.34 \times 10^{-2}\left(3.17 \times 10^{-2}\right.$ to $\left.3.76 \times 10^{-2}\right)$ & $4.80 \times 10^{-2}\left(4.56 \times 10^{-2}\right.$ to $\left.5.51 \times 10^{-2}\right)$ \\
\hline Sand-blasted & $1.02 \times 10^{-2}\left(0.90 \times 10^{-2}\right.$ to $\left.1.20 \times 10^{-2}\right)$ & $2.50 \times 10^{-2}\left(2.15 \times 10^{-2}\right.$ to $\left.2.70 \times 10^{-2}\right)$ & $4.49 \times 10^{-2}\left(4.33 \times 10^{-2}\right.$ to $\left.4.90 \times 10^{-2}\right)$ \\
\hline Acid-etched & $2.16 \times 10^{-2}\left(1.78 \times 10^{-2}\right.$ to $\left.2.49 \times 10^{-2}\right)$ & $3.33 \times 10^{-2}\left(2.96 \times 10^{-2}\right.$ to $\left.3.70 \times 10^{-2}\right)$ & $4.44 \times 10^{-2}\left(4.08 \times 10^{-2}\right.$ to $\left.5.03 \times 10^{-2}\right)$ \\
\hline \multicolumn{4}{|l|}{ Hemidesmosomes } \\
\hline Smooth-polished & $1.01 \times 10^{-1}\left(7.93 \times 10^{-2}\right.$ to $\left.1.07 \times 10^{-1}\right)$ & $1.22 \times 10^{-1}\left(1.14 \times 10^{-1}\right.$ to $\left.1.40 \times 10^{-1}\right)$ & $2.12 \times 10^{-1}\left(1.72 \times 10^{-1}\right.$ to $\left.2.18 \times 10^{-1}\right)$ \\
\hline Machine-finished & $7.75 \times 10^{-2}\left(7.40 \times 10^{-2}\right.$ to $\left.9.36 \times 10^{-2}\right)$ & $1.12 \times 10^{-1}\left(1.06 \times 10^{-1}\right.$ to $\left.1.26 \times 10^{-1}\right)$ & $1.16 \times 10^{-1}\left(7.05 \times 10^{-2}\right.$ to $\left.8.84 \times 10^{-1}\right)$ \\
\hline Sand-blasted & $5.73 \times 10^{-2}\left(5.02 \times 10^{-2}\right.$ to $\left.6.73 \times 10^{-2}\right)$ & $7.07 \times 10^{-2}\left(6.08 \times 10^{-2}\right.$ to $\left.7.65 \times 10^{-2}\right)$ & $5.94 \times 10^{-2}\left(5.72 \times 10^{-2}\right.$ to $\left.6.49 \times 10^{-2}\right)$ \\
\hline Acid-etched & $7.97 \times 10^{-2}\left(6.56 \times 10^{-2}\right.$ to $\left.9.19 \times 10^{2}\right)$ & $1.00 \times 10^{-1}\left(9.18 \times 10^{-2}\right.$ to $\left.1.14 \times 10^{-1}\right)$ & $7.99 \times 10^{-2}\left(7.05 \times 10^{-2}\right.$ to $\left.8.84 \times 10^{-2}\right)$ \\
\hline
\end{tabular}




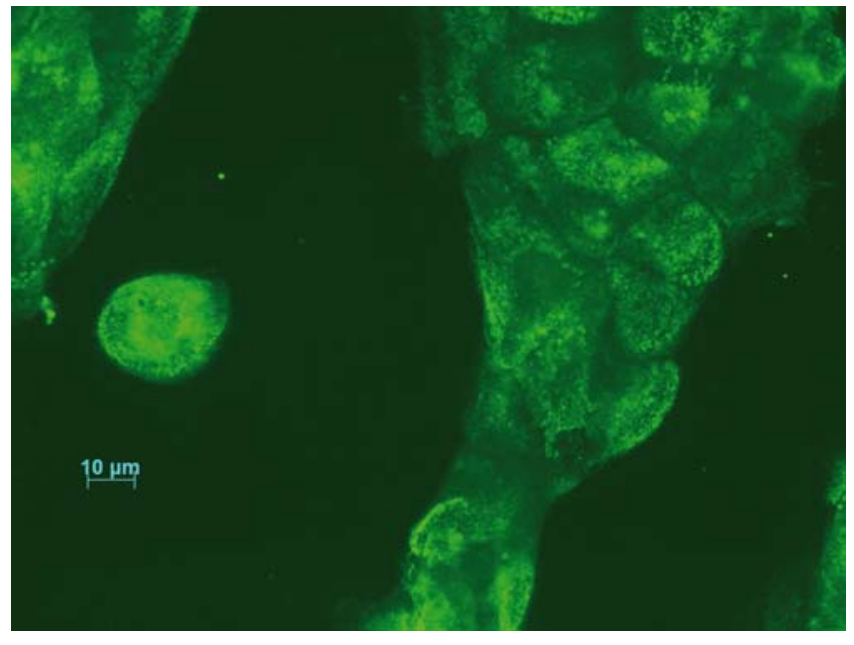

Fig. 2a

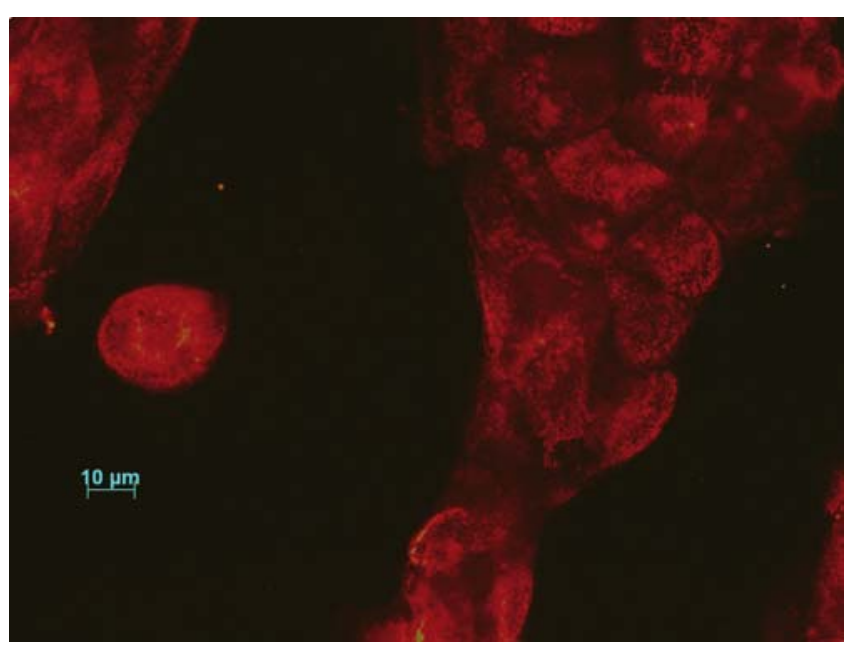

Fig. 2b

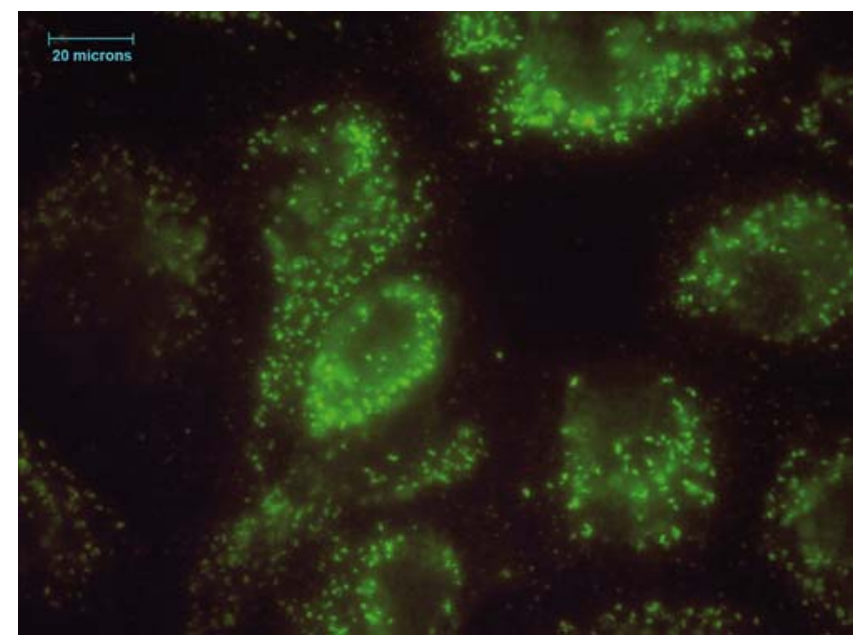

Fig. 2c

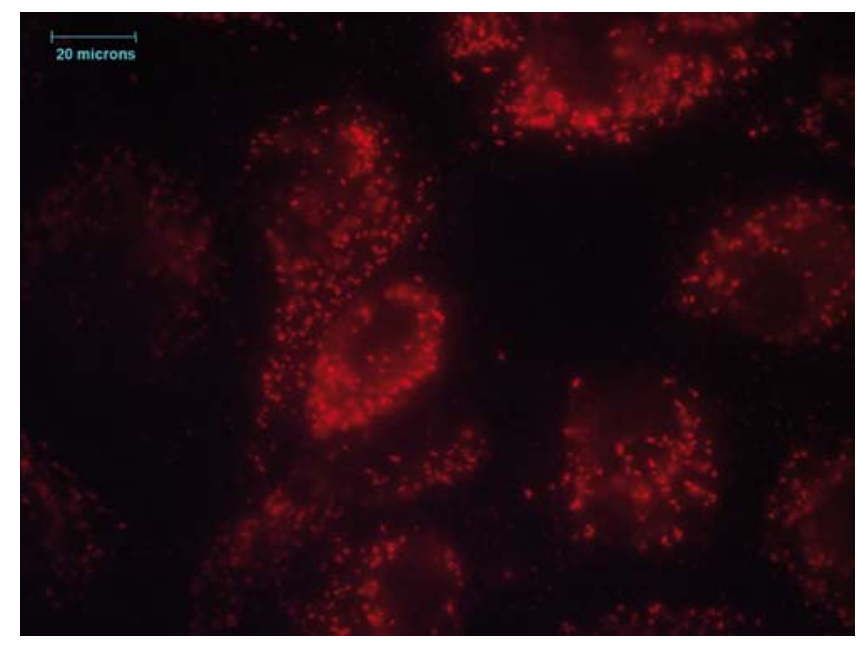

Fig. 2d

Immunofluorescent microscope photomicrographs showing immortalised human keratinocytes after 72 hours with a) and b) $\alpha 6$-integrin staining with fluorescent-isothiocyante, and c) and d) BP 180 co-localisation with Alexa Fluor 568 . These images confirm the presence of hemidesmosomes.

significantly greater numbers of hemidesmosomes per unit cell area compared with the acid-etched discs $(\mathrm{p}<0.05)$. Significant differences were observed between all of the types of material at 72 hours (all p-values, $<0.05$ ). The number of hemidesmosomes per unit cell area was lowest on sand-blasted and acid-etched discs at 48 and 72 hours, respectively.

No staining was observed on the negative control discs irrespective of which secondary antibody was used.

Regression correlation. At all time points, significant negative linear correlations were observed between proliferation and $\mathrm{Ra}, \mathrm{Rz}$ and Sm variables using Spearman's rank correlation analyses $(\mathrm{p}=0.01)$. Proliferation was observed to decrease with increasing topographical parameters. At 24 and 48 hours, correlation coefficients were observed between $\mathrm{Ra}$ and both the numbers of focal adhesions $\left(\mathrm{R}^{2}=0.609, \mathrm{p}=0.01\right)$ and hemidesmosomes $\left(\mathrm{R}^{2}=0.639\right.$, $\mathrm{p}=0.01$ ) per unit cell area. The results show that cell attachment decreased linearly with increasing Ra. By 72 hours there was no significant linear correlation between the variables. At all time points, significant linear negative correlations were observed between both $\mathrm{Rz}$ and $\mathrm{Sm}$, and the number of both focal adhesions $\left(R^{2}=0.639\right.$ and 0.624 , respectively) and hemidesmosomes $\left(R^{2}=0.642\right.$ and 0.698 , respectively) per unit cell area. Cell attachment significantly decreased with increasing $\mathrm{Rz}$ and $\mathrm{Sm}$.

Scanning electron microscopy. After 24 hours, smoothpolished and machine-finished discs supported cell monolayers continuous with the surfaces of the substrate, while the monolayers on acid-etched and sand-blasted discs were inter- 


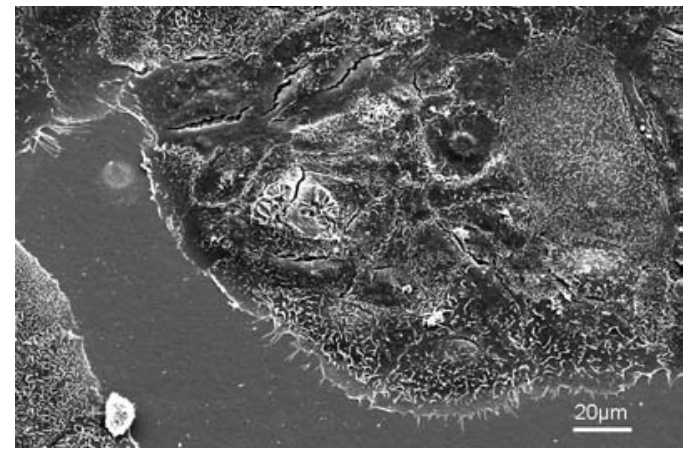

Fig. 3a

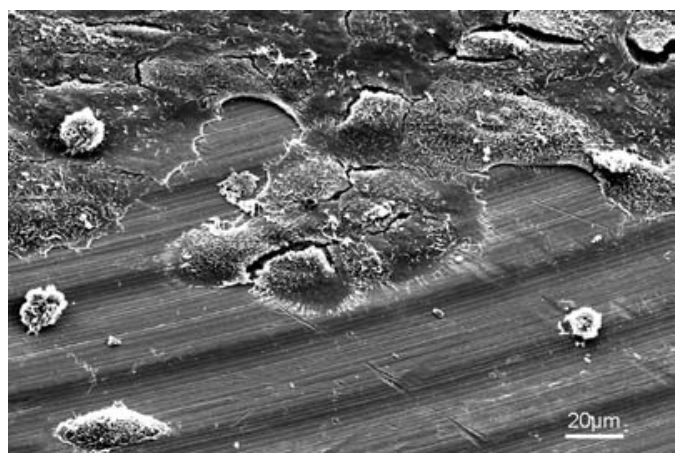

Fig. 3c

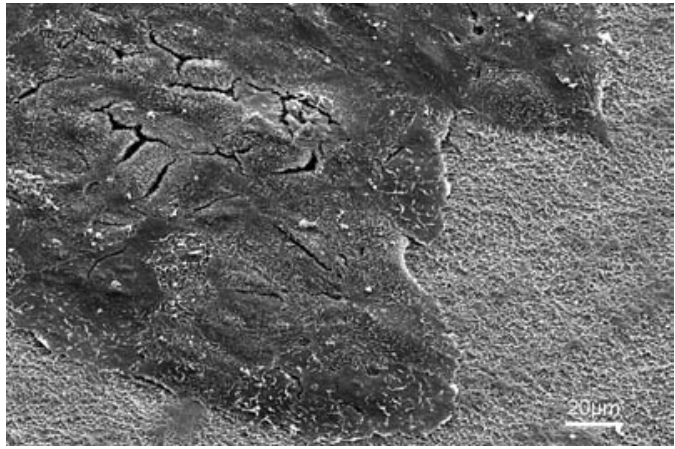

Fig. 3b

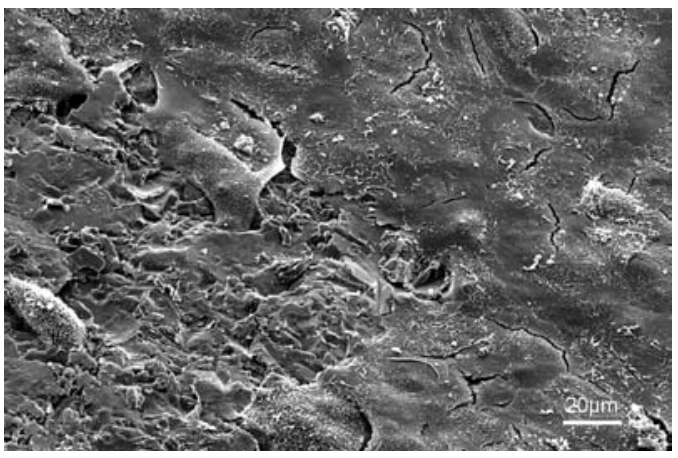

Fig. 3d

Scanning electron microscopy photomicrographs of immortalised human keratinocytes at 24 hours on a) smooth-polished, b) acid-etched, c) machine-finished and d) sand-blasted discs.

rrupted and non-continuous (Fig. 3). Cells adopted a more flattened morphology on smooth-polished and machinefinished substrates compared with acid-etched and sandblasted, on which they appeared rounded with fewer cytoplasmic processes. The cell area was increased on the smoothpolished substrate compared with the machine-finished, acidetched and sand-blasted substrates and persisted at 48 and 72 hours. Stratification into multilayers was observed on smoothpolished and machine-finished substrates after 72 hours.

Transmission electron microscopy. At 72 hours the monolayers on the smooth-polished discs were more closely-packed compared with those on the remaining substrates. Focal adhesions were observed as distinct flattened, electron-dense regions along the membranes of cells cultured on all of the substrates. Hemidesmosomes were observed as electrondense, triangular-shaped cytoplasmic plaques, to which keratin intermediate filaments were attached, along cell membranes adjacent to titanium substrates (Fig. 4). Multiple invaginations of the plasma membranes on acid-etched, machine-finished and sand-blasted discs were observed, with the length and frequency mimicking the undulations of the surface topography. Less frequent and pronounced invaginations were observed in cells cultured on smooth-polished substrates, correlating with the reduction in the values of $\mathrm{Ra}, \mathrm{Rz}$ and Sm (Table I).

\section{Discussion}

The topography of a titanium alloy surface can regulate cell morphology ${ }^{15}$ and the composition of the extracellular matrix, ${ }^{16}$ while the physical state of the latter can dictate the type and frequency of cell-matrix adhesions. ${ }^{21,22}$ In 1978, Folkman and Moscona ${ }^{23}$ demonstrated that cell morphology has a regulatory effect on proliferation, with flattened wellattached cells having a higher proliferative capacity compared with those adopting a rounder and more loosely adhered phenotype. In our study, we observed differences in cell morphology between titanium-alloy substrates with different surface topographies. Smooth-polished substrates supported monolayers of cells with a flatter morphology compared with the rounded phenotypes supported by sand-blasted discs. As observed by Folkman and Moscona, ${ }^{23}$ the respective morphologies of these cell populations were indicative of their proliferative capacities, with regression correlation indicating inverse relationships between surface roughness and cell proliferation over the range of $\mathrm{Ra}, \mathrm{Rz}$ and $\mathrm{Sm}$ values assessed by us. Whether surface roughness dictates cell morphology, which in turn regulates proliferation, or vice versa, remains to be determined. However, numerous reports have provided explanations for an increase in surface roughness causing a decrease in the surface area of the cells. Since spreading of cells is an active process, ridges and troughs in the substrate present 


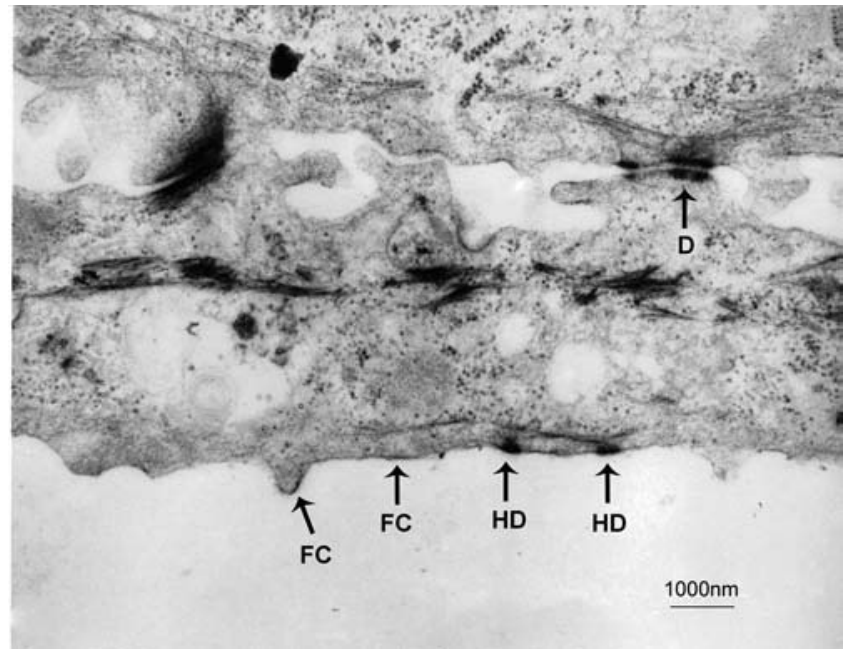

Fig. 4

Transmission electon micrograph of immortalised human keratinocytes cultured on an acid-etched disc at 72 hours (D, desmosomes; FC, focal contacts; HD, hemidesmosomes).

a physical barrier to the progression of migrating cells ${ }^{15}$ and this can be extrapolated to the migration of membranes in cell spreading. In our study, smooth-polished substrates optimised proliferation of keratinocytes compared with acid-etched, machine-finished and sand-blasted materials with increased surface roughness.

In 1985, Jansen et $\mathrm{a}^{24}$ demonstrated that the materials of the substrate can regulate the structure of epithelial cellsubstrate contacts. Cell attachment was observed on apatite and polystyrene, but was absent on titanium and gold. In our study we have demonstated the attachment of keratinocytes through focal adhesions and hemidesmosomes on titanium-alloy substrates, irrespective of the surface topography. Focal adhesions were observed on all substrates, but their numbers were significantly greater on smooth-polished discs at all time points. Regression correlation showed significant negative correlations between increasing values of $\mathrm{Ra}, \mathrm{Rz}$ and $\mathrm{Sm}$ and the frequency of focal adhesions and hemidesmosomes at 24 and 48 hours. Despite the continuation in the trend observed between $\mathrm{Ra}$ and focal adhesion and hemidesmosome assembly, the correlation did not reach significance at 72 hours. We accept that a non-linear relationship may develop with time and that further research is required to determine whether linear relationships would persist with changes in topography on a micro- and nano-scale. We have shown that surface topography influences the morphology of epithelial cells and consider that this affects the composition of the extracellular matrix, which in turn is responsible for the upregulation of the intracellular signalling pathways required for focal adhesion and the assembly of hemidesmosomes. This up-regulation may be lacking on substrates with higher Ra, Rz and Sm parameters. We appreciate that the components of the extracellular matrix such as fibronectin have been implicated in regulating the assembly of focal adhesions, while that of intracellular signalling pathways which emanate from this process controls cell adhesion and spreading. ${ }^{25,26}$ Further work is necessary to determine the composition of the extra-cellular matrix resulting from the topographies of the substrates used here, and whether expression of hemidesmosomes and focal adhesion could be up-regulated by using other topographies which promote production of components of the extra-cellular matrix which optimise adhesion.

In our study, hemidesmosomes were expressed by keratinocytes cultured on the titanium substrates and were observed using immunolocalisation of the $\alpha 6$-integrin subunit and BP 180 by transmission electron microscopy. The assembly and disassembly of hemidesmosomes are vital to numerous epithelial cell processes, including growth, wound remodelling and repair, morphogenesis, and the maintenance of barrier function and homeostasis. ${ }^{27}$ In 1996, Giancotti ${ }^{28}$ proposed that hemidesmosomes were involved in signalling between the intra- and extra-cellular environments, and vice versa, potentially playing a role in more diverse cellular functions such as cell proliferation, differentiation and gene expression. Hemidesmosomes have been shown to be the mechanism by which gingival epithelial cells seal the transcutaneous interface at the normal dentoepithelial junction ${ }^{29}$ and at the transcutaneous implant interface. ${ }^{30}$ Discontinuation of the epithelial layer without attachment to a transcutaneous structure leads to infection since it provides a potential entry for pathogens from the external environment. Having achieved sufficient dermal attachment to prevent epithelial downgrowth in vivo, ${ }^{13}$ achieving a seal at the epithelium-implant interface through hemidesmosomes remains essential for the future of ITAP.

We have used both focal adhesion and the number of hemidesmosomes per unit keratinocyte cell area as an indication of cell-substrate affinity and attachment. We have recently correlated data from the vinculin marker directly to the biophysical strength of attachment in fibroblasts, ${ }^{17}$ and propose further work to demonstrate a parallel with keratinocytes. Recent studies reporting the strength of attachment of keratinocytes to titanium and collagen-GAG substrates have used the presence of cells remaining after washing as a measure of cell adhesion. ${ }^{31}$ We believe that vinculin and the hemidesmosome numbers per unit cell area are more reliable assays of the attachment of keratinocytes to substrate, but this needs to be substantiated by further study. Keratinocyte attachment, measured by using the percentage of adherent cells, has been shown to be significantly enhanced by augmentation of the substrate with fibronectin, ${ }^{32}$ and we postulate that this, combined with optimal surface topography, may be of benefit to ITAP.

In our study, we have shown that the topography of the surface of titanium alloy influences hemidesmosome assembly in keratinocytes in vitro, and that an increase in $\mathrm{Ra}, \mathrm{Rz}$ 
and $\mathrm{Sm}$ in the substrates significantly decreased the expression of hemidesmosomes. Smoother topography increased the assembly rate of focal adhesions at early time points and this has influenced the expression of hemidesmosomes.

We have shown that human keratinocytes are capable of proliferation and attachment on titanium alloy substrates in vitro through focal adhesions and hemidesmosomes. We postulate that reduction of $\mathrm{Ra}, \mathrm{Rz}$ and $\mathrm{Sm}$ results in increased proliferative capacity, focal adhesion and assembly of hemidesmosomes. We propose that a smooth, polished titanium alloy layer, at the epithelial-implant level in an ITAP may optimise attachment of the epithelial layer in vivo. Further studies will be performed to evaluate this and to decrease infection in transcutaneous implants. We hope that a seal at the epithelial-implant interface around the ITAP will result in a successful barrier to infection, and enable transcutaneous implants to be used as successful alternatives to current stump-socket designs for amputees.

No benefits in any form have been received or will be received from a commer cial party related directly or indirectly to the subject of this article.

\section{References}

1. Von Recum AF. Applications and failure modes of percutaneous devices: a review. J Biomed Mater Res 1984;18:323-36.

2. Moens P, Lylle J, Lammens J, Fabry G. Correction of severe deformities of the foot using llizarov's equipment. Rev Chir Orthop Reparatrice Appar Mot 1994;80:118-22 (in French).

3. Ring D, Jupiter JB, Labropovlos PK, et al. Treatment of deformity of the lower limb in adults who have osteogenesis imperfecta. J Bone Joint Surg [Am] 1996;78-A:220-5.

4. Theis JC, Simpson H, Kenwright J. Correction of complex lower limb deformities by the Ilizarov technique: an audit of complications. J Orthop Surg (Hong Kong) 2000;8:67-71.

5. Dudek NL, Marks MB, Marshall SC. Skin problems in an amputee clinic. Am J Phys Med Rehabil 2006;85:424-9.

6. Levy SW. Amputees: skin problems and prostheses. Curtis 1995;55:297-301.

7. Kohler P, Lindh L, Bjorklind A. Bacteria on stumps of amputees and the effect of antiseptics. Prosthet Orthot Int 1989;13:149-51.

8. Branemark PI, Breine U, Adell R, et al. Intra-osseous anchorage of dental prostheses. Scand J Plast Recon Surg 1969;3:81-100.

9. Branemark PI. Tooth replacement by oral endoprostheses: clinical aspects. Int J Oral Implantol 1988;5:27-9.

10. Branemark R, Branemark PI, Rydevik B, Myers RR. Osseointegration in skeletal reconstruction and rehabilitation: a review. J Rehabil Res Dev 2001;38:17581.

11. Sullivan J, Uden M, Robinson KP, Sooriakumaran S. Rehabilitation of the trans-femoral amputee with an osseointegrated prosthesis: the United Kingdom experience. Prosthet Orthot Int 2003;27:114-20
12. Pendegrass CJ, Goodship AE, Price JS, Blunn GW. Nature's answer to breaching the skin barrier: an innovative development for amputees. J Anatomy 2006:209:59-67.

13. Pendegrass CJ, Goodship AE, Blunn GW. Development of a soft tissue sea around bone-anchored transcutaneous amputation prostheses. Biomaterials 2006;27:4183-91.

14. Meredith DO, Eschbach L, Wood MA, et al. Human fibroblast reactions to standard and electropolished titanium and Ti-6A1-7Nb, and electropolished stainless steel. J Biomed Mater Res (Part A) 2005;75:541-55

15. Eisenbarth E, Meyle J, Nachtigal W, Breme J. Influence of the surface structure of titanium mats on the adhesion of fibroblasts. Biomaterials 1996;17:1399-403.

16. Meredith DO, Eschbach L, Riehle MO, Curtis AS, Richards RG. Microtopography of metal surfaces influence fibroblast growth by modifying cell shape, cytoskeleton and adhesion. J Orthop Res 2007: in press.

17. Middleton CA, Pendegrass CJ, Gordon D, Jacob J, Blunn GW. Fibronectin silanized titanium alloy: a bioinductive and durable coating to enhance fibroblast attachment in vitro. J Biomed Mater Res (Part A) 2007;83:1032-8

18. Jones JCR, Hopkinson SB, Goldfinger LE. Structure and assembly of hemidesmosomes. Bioassays 1998;20:488-94.

19. Borradori L, Sonnenberg A. Stucture and function of hemidesmosomes: more than simple adhesion complexes. J Invest Dermato/ 1999;112:411-18.

20. Nievers MG, Kuikman I, Geerts D, Leigh IM, Sonnenberg A. Formation of hemidesmosome-like structures in the absence of ligand binding by the alpha 6 beta 4 integrin requires binding of HD1/plectin to the cytoplasmic domain of the beta 4 integrin subunit. J Cell Sci 2000;113:963-73.

21. Katz BZ, Zamir E, Bershadsky A, et al. Physical state of the extracellular matrix regulates the structure and molecular composition of cell-matrix adhesions. Mol Biol Cell 2000;11:1047-60.

22. Bosman FT, Stamenkovic I. Functional structure and composition of the extracellular matrix. J Pathology 2003;200:423-8.

23. Folkman J, Moscona A. Role of cell shape in growth control. Nature 1978;273:3459 .

24. Jansen JA, De Wijn JR, Wolters-Lutgerhorst JM, Van Mullen PJ. Ultrastructural study of epithelial cell attachment to implant materials. J Dent Res 1985;64:891-

25. Kiyokawa E, Hashimoto Y, Kobayashi S, et al. Activation of Rac1 by a Crk SH3binding protein, DOCK180. Genes Dev 1998;12:3331-6.

26. Barry ST, Flinn HM, Humphries MJ, Critchley DR, Ridley AJ. Requirement for Rho in integrin signaling. Cell Ahes Commun 1997;4:387-98.

27. Kurpakus MA, Quaranta V, Jones JCR. Surface relocation of alpha 6 beta 4 integrins and assembly of hemidesmosomes in an in vitro model of wound healing. J Cell Biol 1991;115:1737-50

28. Giancotti FG. Signal transduction by the alpha 6 beta 4 integrin: charting the path between laminin binding and nuclear events. J Cell Sci 1996;109:1165-72.

29. Hormia M, Owaribe K, Virtanen I. The dento-epithelial junction: adhesion by type-1 hemidesmosomes in the absence of a true basal lamina. J Peridontol 2001;72:788-97.

30. Ikeda H, Yamaza T, Yoshinari M, et al. Ultrastructural and immunoelectron microscopis studies of the peri-implant epithelium-implant (Ti-6AL-4V) interface of rat maxilla. J Peridonto/ 2000;71:961-73.

31. Scheideler L, Ruopp F, Wendel HP, Sathe S, Geis-Gerstorfer J. Photocoupling of fibronectin to titanium surfaces influences keratinocyte adhesion, pellicle formation and thrombogenicity. Dental Materials 2007;23:469-78.

32. Bush KA, Downing BR, Walsh SE, Pins GD. Conjugation of extracellular matrix proteins to basal lamina analogs enhances keratinocyte attachment. J Biomed Mater Res (Part A) 2007;80:444-52. 